\title{
Self-Control Matters: Examining Indirect Use of Hospital Information Systems and its Control Mechanisms
}

\section{Yujing $\mathrm{Xu}$}

Department of Information Systems

City University of Hong Kong

Hong Kong, China

Email: xyujing2-c@my.cityu.edu.hk

\section{Yu Tong}

School of Management

Zhejiang University

Zhejiang, China

Email: tong_yu@zju.edu.cn

\section{Stephen Shaoyi Liao}

Department of Information Systems

City University of Hong Kong

Hong Kong, China

Email: issliao@cityu.edu.hk

\section{Abstract}

The indirect use of hospital information systems (HIS), that is, the indirect interaction of designated physicians with HIS by delegating HIT-related tasks to others, has become a popular phenomenon in hospitals. Indirect use frees physicians from busywork and helps them achieve improved productivity. However, the agency theory and organization literature indicate that the consequences of indirect use may depart from physicians' expectations because of agency problems. To resolve such challenges, prior work places great emphasis on formal control and social control. Considering the nature of hospital settings, this study proposes that an agent's self-control could also be a prominent control mechanism. To obtain a comprehensive understanding, this study builds a research model that depicts the impacts of three control mechanisms and their interplays on indirect use performance. The proposed methodology and preliminary findings are also discussed to provide insights into how to conduct indirect use efficiently and effectively.

Keywords: indirect use, hospital information systems (HIS), self-control, formal control, social control 


\section{Introduction}

As a tool to boost administrative efficiency and support patient care, hospital information systems (HIS), which include electronic medical record systems and computerized physician order entry, have become staple applications in physicians' daily work (Black et al. 2011; Hillestad et al. 2005; Kazley and Ozcan 2008; Poon et al. 2010). In hospitals, the indirect use of HIS, that is, the indirect interaction of designated physicians with HIS by delegating HIT-related tasks to others (Xu et al. 2018; Tong et al. 2017; Tong et al. 2015; Kane and Alavi 2008), has become popular. Many physicians, especially those at the senior level, tend to delegate HIS-related tasks (e.g., data entry) to their subordinates or interns. This indirect use behavior can be understood as a form of agency (Eisenhardt 1989), which involves two parties: principal physicians (who are designated users and choose to delegate HIS-related tasks to others) and agent physicians (who perform the HIS-related tasks on behalf of the principal physicians).

The popularity of indirect use among physicians can be understood from the nature of their work. Although the use of HIS effectively promotes service quality and saves cost, it adds to the workload of physicians who are already facing tight work schedules. Furthermore, physicians prioritize their provision of quality service to their patients. Given a heavy workload, physicians cannot allocate sufficient attention to every patient. Indirect use frees principal physicians from busywork and helps them achieve improved productivity (True et al. 2014). Some researchers recognize the importance of the indirect use of HIS in improving the efficiency and quality of care in healthcare organizations (e.g., Tong et al. 2017; Kane and Alavi 2008; Sykes et al. 2011). For example, Kane and Alavi (2008) verified that indirect use could alleviate principals' busy workload and improve quality of care.

Despite the promises, prior literature in agency theory and organization control indicate that agent behavior may depart from a principal's expectations due to goal conflict and information asymmetry between the two parties (Eisenhardt 1985, 1989; Friedkin 1983; Ouchi and Maguire 1975). The indirect use of HIS, if not managed properly, may also introduce problems to principal physicians. For example, an agent physician's attitude toward the indirect use of HIS may be totally different from that of the principal physician because the agent must bear extra work and delegation could prevent the agent from accomplishing tasks at his/her own pace. Such a conflict has a possible negative effect on the indirect use of HIS. To resolve such challenges, prior work on the principal-agent relationship places great emphasis on two control mechanisms conducted by principals, namely, formal control and social control. Formal control is a control mechanism usually supported by organizational rules that authorizes the principal to monitor the agent's behavior or verify the outcome (Jaworski 1988). Social control engenders a close tie between the principal and the agent through trust and shared norms and values (Li et al. 2010; Poppo and Zenger 2002). Although these two control mechanisms are pivotal, as suggested by the literature, this study posits that the nature of the hospital setting could weaken their effectiveness. Specifically, given that agent physicians are usually junior physicians who are required to periodically rotate between different medical units/hospitals, principal physicians cannot physically establish a stable relationship with and effectively implement control over the same agent physicians.

Under such circumstances, this study proposes that an agent physician's self-control could be a prominent control mechanism. Different from formal control and social control, self-control is conducted by the agent to adjust inappropriate behavior by establishing individual goals and monitoring what has been achieved (Jaworski 1988; Kirsch 1996). This type of control mechanism has not been a major focus in the literature (Thaler and Shefrin 1981). Few studies examine the impact of self-control from the agents' perspective. To obtain a comprehensive understanding of control mechanisms for physicians' indirect use of HIS, this paper proposes a research model that depicts the impacts of three control mechanisms and their interplays on indirect HIS use performance. To evaluate the research model, this study is in the process of conducting a multi-method study in a hospital. This project aims to provide insights into how to perform indirect use efficiently and effectively.

\section{Theoretical Background and Hypotheses Development}

\subsection{Control Mechanisms}

The core issue in delegation is the principal-agent relationship (Holmstrom and Milgrom 1991). Austin (2001) generalized the central problem in an agency relationship as how to motivate the agent to behave in the interest of the principal. Control mechanisms can direct the principal and agent's cooperation by regulating the agent's behavior, which greatly influences the success of indirect HIS use (Fryxell et al. 2002). Choosing effective control mechanisms is needed when managing the relationship between the principal and the agent (Jap and Ganesan 2000). The literature on agency theory and organization 
control focus on two dominant categories of control mechanisms, namely, formal control and social control. Hence, little attention has been paid to self-control.

Formal control is a written, management-initiated mechanism by which the probability that the agent behaves in the interest of the principal will be affected (Jaworski 1988). By relying on formal control, the individual principal can monitor, direct, and evaluate what the agent has done (Anderson and Oliver 1987). However, formal control is associated with the authority of the principal and a long-term relationship between the principal and the agent. Therefore, it may be not effective in the healthcare work context because of the high mobility of medical teams.

Unlike formal control, social control may not be supportive of the stated organization objectives (Jaworski 1988). This type of control is localized to the work unit, that is, a medical team in a hospital. Two different views about social control can be found in previous studies. Social control engenders a close tie between the principal and the agent. However, social control is realized by slow accumulation. Moreover, the high mobility of medical teams cannot guarantee the long-term trust between the principal and the agent.

Self-control in which individuals set their own goals, are intrinsically motivated to complete their tasks to achieve their objectives, and evaluate their final performance as work progresses (Kirsch and Cummings 1996). The source of self-control is an individual's intrinsic motivation. Hwang (2005) and Malhotra (2002) claimed that self-control is based on the individual's intrinsic motivation of perceived enjoyment. In other words, the extent to which helping principals accomplish HIS-related tasks is perceived to be enjoyable and pleasant in agents' own right, apart from the instrumental value of the delegation. In the IS literature, self-control and its intrinsic motivation have been suggested as effective interventions to enhance system adoption (Malhotra and Murnighan 2002; Venkatesh and Davis 2000). Owing to its advantages in confining individuals' inappropriate behavior, self-control is associated with positive managerial practices, such as improved satisfaction or performance (Hwang 2005; Kirsch and Cummings 1996). For example, Venkatesh (1999) reported that the game-based training method, which enhances intrinsic motivation (self-control), has higher user satisfaction than the traditional training method does.

Given that many key relationships in the IS use context are not governed by formal organizational mechanisms, Kirsch (1996) argued that a balance exists between autonomous self-control and other control modes. For example, self-control is dependent on the extent to which outcomes are measurable and on the level of the principals' knowledge about direct system use. Thus, self-control and formal and social control have a non-substitutive relationship, and they interact with each other. Specifically, additional behavior observability and outcome measurability may have a negative interactive effect on self-control. This situation is caused by the agent's perception of restrictions. By contrast, agents who have much discretion or freedom in managing delegated tasks are more likely to use self-control and have better achievement than those who have less (Manz and Angle 1986).

\subsection{Hypotheses Development}

Based on the phenomenon of indirect use of HIS in hospital, we propose the hypotheses.

\subsubsection{Impact of Self-control on Indirect HIS Use Performance}

Agents' behavior related to delegated tasks may be self-determined, controlled, or motivated (Hwang 2005). Self-determination theory (Deci and Ryan 1985) indicates that developing an elaborate and unified sense of self is a natural and innate appeal for individuals. Self-control focuses on how agents regulate their own actions by developing a coherent sense of oneself. Self-control is associated with positive managerial practices, such as improved satisfaction or performance (Hwang 2005; Kirsch and Cummings 1996).

For agent physicians who perform the delegated HIS-related tasks with self-control, they themselves are the controllers. They believe that accomplishing these tasks is enjoyable and pleasant; thus, they set personal goals and monitor how well they have done over time and intrinsically reward themselves for completing the job. This type of control mechanism is different from formal organizational control mechanisms or professional norms. The agents commit to these tasks and achieve an improved performance in terms of effectiveness and efficiency, thereby finally contributing to the principals' indirect use of HIS. Obviously,

H1: Self-control is positively associated with indirect HIS use performance. 


\subsubsection{Comparison between Self-control and Other Control Mechanisms}

Based on agency theory and organization control theory, formal and social control can bridge the gap between the principal and the agent in terms of goal conflict and information asymmetry (Eisenhardt 1989; Ouchi and Maguire 1975). Formal control restricts the inappropriate behavior of agents with HISrelated tasks by verifying the outcome or monitoring and directing their behavior (Anderson and Oliver 1987). Social control organizes agents' behavior through relationship governance or socialization (Jaworski 1988; Poppo and Zenger 2002).

Principal physicians delegate HIS-related tasks to agent physicians, who are also usually in the same medical team. Although previous studies have confirmed that formal and social control used by principals can ensure that agents behave in the interest of the principals to a certain degree (Celly and Frazier 1996; Li et al. 2010; Lui 2009), both control mechanisms are subject to the high mobility of the healthcare work context. They depend on the relationship between principal physicians and agent physicians. In addition, formal control relies on the authority of principal physicians supported by stated organizational rules and objectives. Under this circumstance, high mobility weakens their usefulness. At the same time, because self-control is a function of agents' own intrinsic motivation, it cannot be affected by medical teams' mobility and principals' characteristics. On this occasion, agents' self-control seems increasingly useful in ensuring that agent physicians behave correctly due to its advantages in confined inconformity. As a result, the following hypotheses can be derived.

H2: Formal control is positively associated with indirect HIS use performance.

H2b: Self-control is more positively associated with indirect HIS use performance than formal control is.

H3: Social control is positively associated with indirect HIS use performance.

$H_{3} b$ : Self-control is more positively associated with indirect HIS use performance than social control is.

\subsubsection{Moderating Effect of Formal Control and Social Control}

Self-control, formal control, and social control share a non-substitutive relationship (Kirsch 1996; Kirsch and Cummings 1996). For example, social control may enhance the extent of self-control due to the trust perceived by agent physicians from principal physicians (Lui 2009). Enhanced self-control leads to an improved performance of agent physicians in delegated tasks. Thus, social control mechanisms may positively moderate the effect of self-control on indirect HIS use.

In addition, Manz and Angle (1986) suggested that self-control in a discretionary and free environment can lead to improved achievement. Therefore, the high level of behavior and outcome observability (formal control) suggest that principal physicians closely supervise agent physicians, thereby resulting in little freedom for agent physicians to manage delegated HIS-related tasks. In turn, this process reduces the impact of self-control on the indirect use of HIS. By contrast, social control provides agents additional autonomy to handle the work. An agent who has much discretion or freedom in managing delegated tasks is likely to use self-control and attain considerable achievements. Under such an environment, agent physicians can work at their own pace. In addition, the intrinsic motivation of enjoyment makes agent physicians actively engage in delegated HIS-related tasks. Specifically, the following hypotheses are derived.

H4: Formal control negatively moderates the relationship between self-control and indirect HIS use performance.

H5: Social control positively moderates the relationship between self-control and indirect HIS use performance.

\section{Proposed Methodology and Preliminary Findings}

The indirect use of HIS reflects a complex activity of physicians within the context and environment of a hospital. To investigate this phenomenon and evaluate the proposed hypotheses, this study is now in the process of refining the research model through a case study that follows the sequential multi-method research approach (Mingers 2001). Qualitative data collected from physicians can provide a full understanding of the research context. Furthermore, a case study can disclose information about the reasoning behind the different effects of control mechanisms on indirect HIS use performance. Then, a contextualized research model will be formulated on the basis of the analysis of the case study. A 
positivist approach will then be employed to form a substantial and systematic view of the indirect use of HIS.

A large public general hospital in China with approximately 2,000 physicians is selected for this study. In this hospital, physicians directly interact with the HIS and indirectly interact with it by delegating some HIS-related tasks to their subordinates or colleagues. The choice of a single hospital enables us to detect individual-level effects and avoid inter-hospital differences.

The qualitative data will be collected in two to three months. The data gathering techniques used include onsite observations and interviews with IS professionals and 10-dyad physicians, who are principal physicians and agent physicians, respectively. As a first step in data collection, 10 physicians, including five principal physicians and five agent physicians from different departments, have been interviewed. The interview began with questions related to their basic information, such as their age, position, and job description. Then, for the principal physicians, questions about their direct and indirect use of HIS and the control mechanisms they used were asked; For the agent physicians, questions about how they help the principal physicians accomplish HIS-related tasks and how the control mechanisms guide their behavior were asked. The interviews were open-ended and interactive. The interviewees were prompted to answer by using examples, especially for points relevant to our focus. Each interview lasted 30 minutes to 1 hour.

\begin{tabular}{|c|c|c|c|c|c|c|}
\hline No. & Department & Sex & Position & $\begin{array}{l}\text { Role in } \\
\text { indirect } \\
\text { use }\end{array}$ & Code & Quote \\
\hline \multirow[t]{2}{*}{1} & Oncology & $\mathrm{F}$ & $\begin{array}{l}\text { Associate } \\
\text { Chief } \\
\text { Physician }\end{array}$ & Principal & $\begin{array}{l}\text { - Attitude } \\
\text { towards } \\
\text { indirect } \\
\text { use }\end{array}$ & $\begin{array}{l}\text { It (indirect use) eased me of } \\
\text { my burden, and I have more } \\
\text { time to deal with things that } \\
\text { only senior physician can do. }\end{array}$ \\
\hline & & & & & $\begin{array}{ll}\text { - } & \text { Self- } \\
& \text { control }\end{array}$ & -.rely on their autonomy. \\
\hline \multirow[t]{3}{*}{2} & Oncology & $\mathrm{F}$ & $\begin{array}{l}\text { Resident } \\
\text { Physician }\end{array}$ & Principal & $\begin{array}{l}\text { - Attitude } \\
\text { towards } \\
\text { indirect } \\
\text { use }\end{array}$ & $\begin{array}{l}\text { As the principal: new interns } \\
\text { are not familiar with the } \\
\text { systems... sometimes they did } \\
\text { bad...but after my training, } \\
\text { they do better can help me a } \\
\text { lot. }\end{array}$ \\
\hline & & & & & & $\begin{array}{l}\text { As the agent: it (indirect use) } \\
\text { is my duty. }\end{array}$ \\
\hline & & & & & $\begin{array}{ll}\text { - } & \text { Self- } \\
& \text { control }\end{array}$ & $\begin{array}{l}\text { Of course, self-control is the } \\
\text { most important thing. }\end{array}$ \\
\hline 3 & Orthopaedics & M & Intern & Agent & $\begin{array}{l}\text { - Attitude } \\
\text { towards } \\
\text { indirect } \\
\text { use }\end{array}$ & $\begin{array}{l}\cdots \text { (Data entry) it is a waste of } \\
\text { time, I can learn little from it. }\end{array}$ \\
\hline
\end{tabular}

Table 1. Example of Quotes for Codes

The transcribed interview data were first organized and coded on the basis of this set of themes. Sample quotes from these interviews are listed in Table 1. Through a preliminary analysis of these qualitative data, we identified some important findings. To guarantee the reliability of the findings, we made sure that each finding was supported by at least two sources (Klein and Myers 1999). We moved back and forth between data, theoretical lenses, and the refined model until "theoretical saturation" was reached, at which point the incremental improvement of the model was minimal and comprehensively explaining the findings of the qualitative data was possible.

First, we find that indirect HIS use behavior is popular and that it has even become a norm among physicians. On the basis of the dialogues with physicians, the reasons that lead to the indirect use of HIS can be summarized into four categories. 
- $\quad$ To free oneself from busy workload

- $\quad$ To guide junior physicians and interns in performing treatment by using HIS

- $\quad$ For those who have limited computer literacy, indirect use improves work efficiency and avoids embarrassment

- $\quad$ For those who value hierarchies, the right to delegate HIS-related tasks makes them feel identified

This study will mainly focus on the first two categories because they account for the most proportion of indirect use of HIS in the target hospital.

Second, the indirect use of HIS liberates principal physicians from a heavy workload, thereby allowing them to concentrate on patient treatment operation and improve their productivity to a certain degree. For example, an agent physician told us that his supervisory physician needed more than three hours to prepare medical records without his help.

In terms of control mechanisms, we observe a non-substitutive relationship among the three control mechanisms. Three of the five principal physicians mentioned that they would use some of the three control mechanisms at the same time. However, a junior principal physician claimed that whether indirect use is helpful depends on the task type. Furthermore, approximately 90\% of the interviewees admitted or emphasized the significant effect of self-control. This finding is consistent with our hypotheses. All agent physicians agreed with our argument that the trust of principal physicians would enhance their self-control performance. However, when referring to the attitude toward delegation, the male and female participants expressed different feelings distinctly. Thus, we will consider sex a control variable in the following study.

In the future, additional qualitative data will be collected from principal physicians and agent physicians in departments that we have yet to address in the target hospital to enrich our findings and further modify our proposed research model. Then, to verify the proposed refined model, we will conduct a survey in the same hospital. We will also design two different questionnaires for principal physicians and agent physicians. Items from our previous study will be revised to correspond to our research context. Specifically, the proposed model will help us form a comprehensive picture of indirect use and its control mechanism.

\section{Expected Contribution}

This study is one of the early attempts to theoretically study the effects of different control mechanisms and their interplays on indirect HIS use performance. Therefore, this study has implications for both theory and practice. Theoretically, this study hopes to advance the current understanding of indirect HIS use in terms of different control mechanisms. The literature on indirect use by IS centrality ignores the goal conflict and information asymmetry between principal physicians and agent physicians. Thus, we must study different control mechanisms that can govern agent physicians' behavior. Additionally, the literature on agency theory and organization control primarily focus on formal control and social control. By contrast, the high mobility of healthcare work weakens the effects of these two dominant control mechanisms. Meanwhile, the advantage of self-control in bounding an individual's own behavior is one of our focuses. By incorporating self-control to examine indirect HIS use, this study effectively supplements the agency literature.

Furthermore, this study offers important implications for practitioners. First, this study illustrates different control mechanisms in aligning the agent's behavior and emphasizes the pivotal role of selfcontrol in the healthcare work context. By using appropriate control mechanisms when delegating HISrelated tasks to others, principal physicians can enjoy improved performance. In addition, an improved understanding of indirect HIS use and its different control mechanisms can help principal and agent physicians in making long-term plans. In sum, this study will provide valuable knowledge for healthcare shareholders to understand how to employ HIS effectively and efficiently through indirect use.

\section{References}

Anderson, E., R.L. Oliver. 1987. "Perspectives on Behavior-Based Versus Outcome-Based Salesforce Control Systems,". Journal of Marketing (51:4), pp. 76-88.

Austin, R.D. 2001. "The Effects of Time Pressure on Quality in Software Development: An Agency Model," Information Systems Research (12:2), pp. 195. 
Black, A.D., J. Car, C. Pagliari, C. Anandan, K. Cresswell, T. Bokun, B. McKinstry, R. Procter, A. Majeed, A. Sheikh. 2011. "The Impact of eHealth on the Quality and Safety of Health Care: A Systematic Overview," PLoS Medicine (8:1), pp. 1-16.

Celly, K.S., G.L. Frazier. 1996. "Outcome-based and behavior-based coordination efforts in channel relationships," Journal of marketing research, pp. 200-210.

Deci, E.L., R.M. Ryan. 1985. Intrinsic motivation and self-determination in human behavior. Springer Science \& Business Media.

Eisenhardt, K.M. 1985. "Control: Organizational and Economic Approaches," Management Science (31:2), pp. 134-149.

Eisenhardt, K.M. 1989. "Agency Theory: An Assessment and Review," The Academy of Management Review (14:1), pp. 57-74.

Friedkin, N.E. 1983. "Horizons of observability and limits of informal control in organizations," Social Forces (62:1), pp. 54-77.

Fryxell, G.E., R.S. Dooley, M. Vryza. 2002. "After the ink dries: the interaction of trust and control in US - based international joint ventures," Journal of Management Studies (39:6), pp. 865-886.

Hillestad, R., J. Bigelow, A. Bower, F. Girosi, R. Meili, R. Scoville, R. Taylor. 2005. "Can Electronic Medical Record Systems Transform Health Care? Potential Health Benefits, Savings, And Costs," Health Affairs (24:5), pp. 1103-1117.

Holmstrom, B., P. Milgrom. 1991. "Multitask principal-agent analyses: Incentive contracts, asset ownership, and job design," Journal of Law, Economics, \& Organization, pp. 24-52.

Hwang, Y. 2005. "Investigating enterprise systems adoption: uncertainty avoidance, intrinsic motivation, and the technology acceptance model," European Journal of Information Systems (14:2), pp. 150-161.

Jap, S.D., S. Ganesan. 2000. "Control mechanisms and the relationship life cycle: Implications for safeguarding specific investments and developing commitment," Journal of marketing research (37:2), pp. 227-245.

Jaworski, B.J. 1988. "Toward a Theory of Marketing Control: Environmental Context, Control Types, and Consequences," Journal of Marketing (52:3), pp. 23-39.

Kane, G.C., M. Alavi. 2008. "Casting the Net: A Multimodal Network Perspective on User-System Interactions," Information Systems Research (19:3), pp. 253-272.

Kazley, A.S., Y.A. Ozcan. 2008. "Do Hospitals With Electronic Medical Records (EMRs) Provide Higher Quality Care?: An Examination of Three Clinical Conditions," Medical Care Research and Review (65:4), pp. 496-513.

Kirsch, L.J. 1996. "The Management of Complex Tasks in Organizations: Controlling the Systems Development Process," Organization Science (7:1), pp. 1-21.

Kirsch, L.J., L.L. Cummings. 1996. "Contextual influences on self-control of is professionals engaged in systems development," Accounting, Management and Information Technologies (6:3), pp. 191219.

Li, Y., E. Xie, H.-H. Teo, M.W. Peng. 2010. "Formal control and social control in domestic and international buyer-supplier relationships", Journal of Operations Management (28:4), pp. 333344 .

Lui, S.S. 2009. "The Roles of Competence Trust, Formal Contract, and Time Horizon in Interorganizational Learning," Organization Studies (30:4), pp. 333-353.

Malhotra, D., J.K. Murnighan. 2002. "The Effects of Contracts on Interpersonal Trust," Administrative Science Quarterly (47:3), pp. 534-559.

Malhotra, Y. 2002. "Is knowledge management really an oxymoron? Unraveling the role of organizational controls in knowledge management" Knowledge mapping and management, pp. $1-13$.

Manz, C.C., H. Angle. 1986. "Can group self-management mean a loss of personal control: Triangulating a paradox," Group \& Organization Management (11:4), pp. 309-334. 
Mingers, J. 2001. "Combining IS research methods: towards a pluralist methodology," Information systems research (12:3), pp. 240-259.

Ouchi William, G. 1979. "A Conceptual Framework for the Design of Organizational Control Mechanism," Management Science (25:9), pp. 833-848.

Poon, E.G., A. Wright, S.R. Simon, C.A. Jenter, R. Kaushal, L.A. Volk, P.D. Cleary, J.A. Singer, A.Z. Tumolo, D.W. Bates. 2010. "Relationship Between Use of Electronic Health Record Features and Health Care Quality: Results of a Statewide Survey," Medical Care (48:3), pp. 203-209.

Poppo, L., T. Zenger. 2002. "Do formal contracts and relational governance function as substitutes or complements?" Strategic management journal (23:8), pp. 707-725.

Sykes, T.A., V. Venkatesh, A. Rai. 2011. "Explaining physicians' use of EMR systems and performance in the shakedown phase," Journal of the American Medical Informatics Association (18:2), pp. 125130.

Thaler, R.H., H.M. Shefrin. 1981. "An Economic Theory of Self-Control," Journal of Political Economy (89:2), pp. 392-406.

Tong, Y., H.-H. Teo, C.-H. Tan. 2008. "Direct and Indirect Use of Information Systems in Organizations: An Empirical Investigation of System Usage in a Public Hospital". ICIS 2008 Proceedings, pp. 138.

Tong, Y. C.-H. Tan, H.-H. Teo. 2017. "Direct and Indirect Information System Use: A Multimethod Exploration of Social Power Antecedents in Healthcare ". Information System Research.

True, G., G.L. Stewart, M. Lampman, M. Pelak, S.L. Solimeo. 2014. "Teamwork and delegation in medical homes: primary care staff perspectives in the Veterans Health Administration," Journal of general internal medicine (29:2), pp. 632-639.

Venkatesh, V. 1999. "Creation of favorable user perceptions: exploring the role of intrinsic motivation," MIS quarterly, pp. 239-260.

Venkatesh, V., F.D. Davis. 200o. "A theoretical extension of the technology acceptance model: Four longitudinal field studies," Management science (46:2), pp. 186-204.

Xu, Y., Tong, Y., Shaoyi S, Liao., Zhou, G., Yu, Y. 2018. "Understanding indirect system use of junior employees in the context of healthcare," Information \& management, vol. 55, no. 6, pp. 759-770.

\section{Acknowledgements}

This work was supported by the National Natural Science Foundation of China (grant numbers 71502155); and the development grant from Shenzhen Science, Technology and Innovation Commission (grant number JCYJ20160229165300897).

\section{Copyright}

Copyright: (C) 2018 authors. This is an open-access article distributed under the terms of the Creative Commons Attribution-NonCommercial 3.0 Australia License, which permits non-commercial use, distribution, and reproduction in any medium, provided the original author and ACIS are credited. 